\title{
Bitrix24 - integrated business-information system for sales process support
}

\author{
Marta Alić \\ University of Applied Sciences, Zagreb \\ Vrbik 8, Zagreb, Croatia \\ marta.alic@zg.htnet.hr
}

\section{Summary}

With the development of information technology, its increased application in the organization of the business process has emerged. In order to manage and keep track with shifting modern markets, companies started to automatize its processes and improve internal and external communication, as a first postulate of agility to keep track with new trends. The implementation of complex, integrated business and information systems is the first step. This paper gives the overview of Bitrix24 system basic functions as a cloud network solution that integrates the customer relationship management (CRM) with the information systems of the entire company.

Keywords: Bitrix24, information system, business process, project management, customer relationship system, document management, human resources

\section{Introduction}

Bitrix24 is an integrated business system, realized as an intranet network in the cloud environment, that connects multiple information systems of various business processes in the company.

The base system is a CRM (Customer Relationship Management) system, which requires joint efforts of all departments of the company, supporting marketing and sales business functions [1].

Regarding the purpose and use [2] of such systems, Bitrix24 is a compound system of customer relationship management which:

1. supports collaboration and communication with customers, partners and suppliers,

2. allows the construction of the employee communication and collaboration along the organizational structure of the company and

3 . supports business process automation.

Bitrix 24 is a business network based on the principles of the social network paradigm. At the base of the system is activity feed, as a basic form of interaction among employees. Every employee can see the latest news and track changes that took place within the company and interact with them. Through this interface one can easily schedule an event, organize a poll, upload files and/or make 
a post as a part of a project management IS. Functionalities of requests (for business trip approval, leave approval, purchase requests, etc.) made from customizing forms in the interface can serve as integral part of the human resources (HR) and accounting information systems.

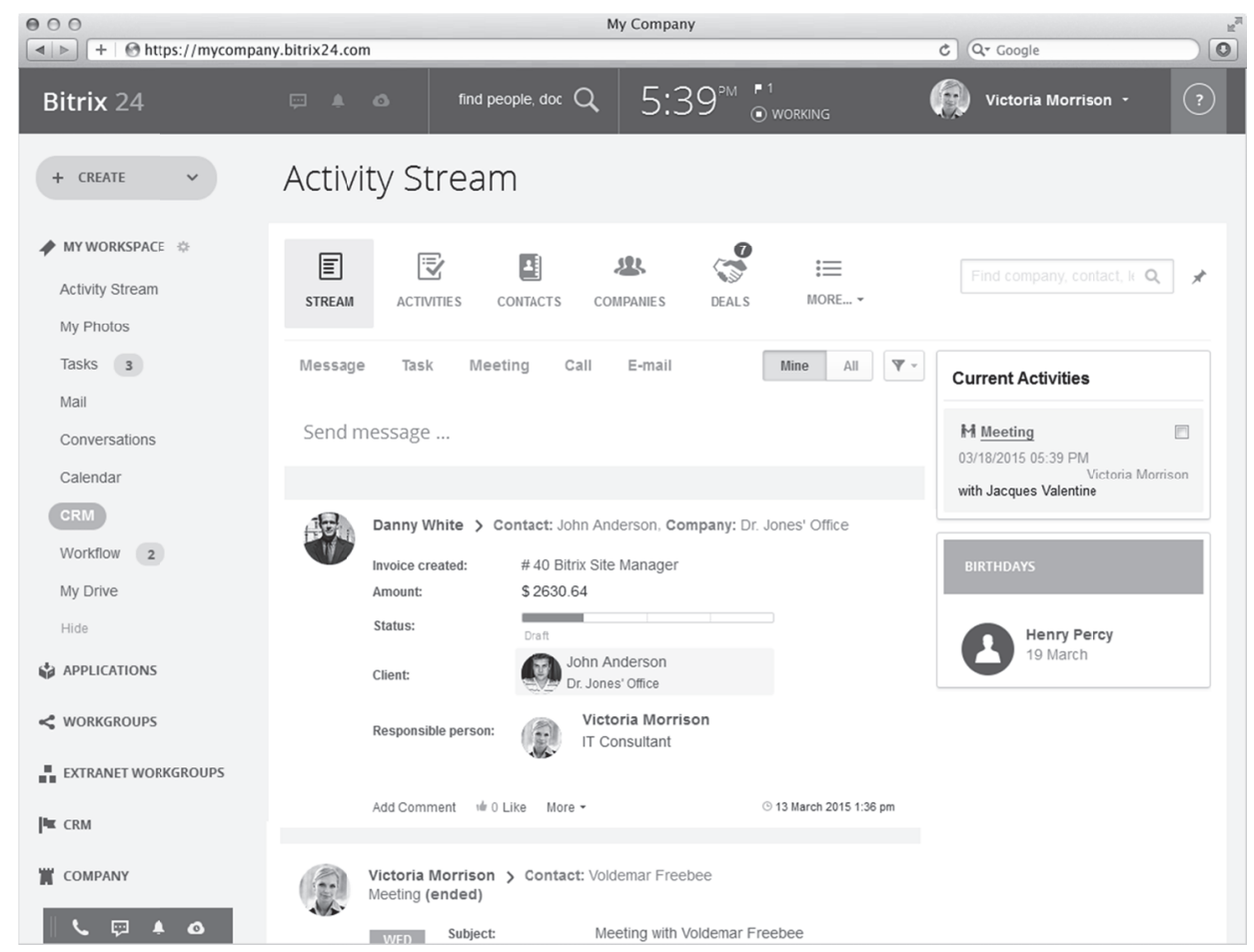

Figure 1. Activity stream workspace (source: https://www.bitrix24.com/features/crm.php)

\section{CRM system}

As a CRM system, Bitrix24 offers easy automation of business processes through the default workflow or by building customized ones. Business processes can include various actions on elements of the system; such as sending emails, assigning responsible persons, making tasks; and operations of the overall document management system (DMS): from record management to archiving. Based on the lead management methodology, the system serves as a bridge between marketing and sales information systems.

Lead is a CRM object that represents a buyer's interest in a product or service and it is usually a result of the organization's marketing strategy and actions through various sales channels (website, social networks, direct sales channels, etc.). By passing through system leads are being qualified and prioritized according to their level of the realization possibility. At the end of a process, leads can be qualified as junk or quality leads. First ones are then being removed from 
system or sent back for remarketing, while second ones are being converted to deal.

Deals are system objects of sales business processes that contain the interaction with a buyer pertaining to a transaction. Deals proceed through the system by a number of customizable statuses given by the system or customized by a workflow and they result with a closed sale (won or lost). At this stage of the sales process, system offers the possibility of quote generation, accompanied with referring invoice, as two new objects in system, connected with accounting operations IS and DMS.

\section{Project and task management}

Through the system for the organization of operational processes in sales, Bitrix 24 in its structure clearly follows the mentioned stages of lead management and sales process, integrating them with the system for project management. When setting clear organizational structure of departments and functional units in system adjustment phase, same structure is easy to follow for adjustment of the organization internal communication system. Every unit can be set as one workgroup, sub-system network where employees within have every functionality of the entire system and where all collaboration and work is documented on activity feed. Projects are also structured through workgroups, giving the possibility of organizing team of employees from different units and on different functions with the same document management panel. When a new version of the document is loaded, the previous is not deleted, but is stored in order to be available at all times and records history provides information about the time when the version created and the user who created it.

Documents can be edited in a cloud with providing Google Docs and Microsoft Office Online tools for text documents, spreadsheets, and presentations on cloud or locally on the computer and by saving they are easily indexed and subject to search, as well as all records of activities, messages or system objects. By creating a project task, time management option is enabled that keeps track of task duration and enable transparent performance reports of the project at any time. Employees can independently input and record absence days through the system. Reports can be made for each department and for each employee on weekly, monthly or annual terms, supporting also HR management.

\section{Product catalog}

Bitrix24 system comprises of the product catalog as an important part of customers relations and sales process. Products can be categorized in sections and have a range of settings options in the system (tax rates, units of measure, currency) as well as customizing options for fields and attributes. They are easily connected with lead and deal objects in the system, giving more detailed overview of realized sales. 


\section{Management support}

One of the major benefits of CRM system implementation is its support to the management. With evolved reporting IS CRMs are often used for planning and forecasting of future sales activities.

Bitrix 24 offers a detailed statistical report of sales business processes by individual components - objects, their status and the persons responsible. There are also embedded reports by products, activities and invoices sent and revenue made. Bitrix 24 in its purpose is not analytical system and in-depth analyzes and forecasts cannot be made within the system, so the segmented data are used primarily for optimization of business processes and as raw data for redistribution.

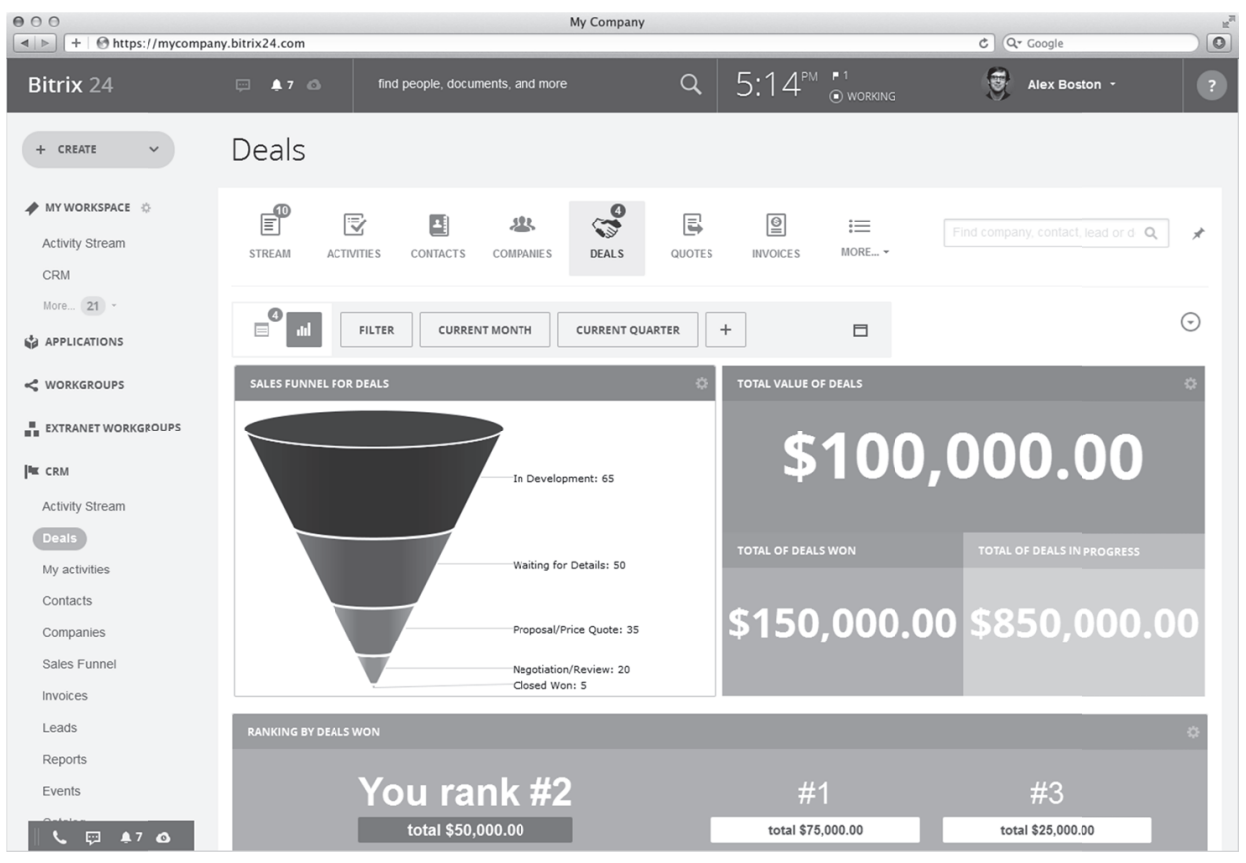

Figure 2. CRM report dashboard (source: https:/www.bitrix24.com/features/crm.php)

\section{Conclusion}

By introducing elements of social networks in the communication and collaboration processes, Bitrix 24 system sets different approach to their organization. Although primarily designed to support the sales processes and customer relations, the system sets wider functionalities of business management, incorporating information systems of document management and project management, human resources, accounting and product catalog functionalities; providing automatization of related activities. Guided by the principles of project management, system analyzes complex processes to simple operations that, accompa- 
nied with a social networking component, gives a unique approach to organization of business, making Bitrix 24 more than just CRM system, but complex business platform.

\section{References}

Bibiano, Luis; Mayol, Enric; Pastor, Joan Role and importance of business processes in the implementation of CRM systems. : Zaragoza: JISBD, 2007.

Harewood, Alton ERP, CRM and BPM vs. Business Process Optimization. May 13th, 2013 $\mathrm{http} / / /$ blogs.aspect.com/2013/05/13/erp-crm-and-bpm-vs-business-process-optimization/ (May 20th, 2015)

Nguyen, Bang The dark side of customer relationship management: Exploring the underlying reasons for pitfalls, exploitation and unfairness, Journal of Database Marketing \& Customer Strategy Management. 19 (2012), 56-70

Srića, Velimir; Muller, Josip. Upravljanje odnosima s klijentima. Zagreb: Delfin - razvoj managementa, 2005. 